\title{
Effects of Soybean Stover-Derived Biochar on Microbial Community and Structure in Loess Soil
}

\author{
Baowei Zhao $\dagger$, Alexandar J. Niebuhr, Yude Lv and Khamhak Douangdalangsy
}

School of Environmental and Municipal Engineering, Lanzhou Jiaotong University, Lanzhou 730070, Gansu, P. R. China †Corresponding author: Baowei Zhao; zhbw2001@ sina.com

Nat. Env. \& Poll. Tech. Website: www.neptjournal.com

Received: 15-07-2019 Accepted: 06-10-2019

\section{Key Words:}

Biochar; Soil microbial community; Lysobacter; Loess soil; Soybean stover

\begin{abstract}
Soil microorganisms play a crucial role in nutrient availability and overall soil health. However, the effects that biochar has on soil microbial communities are not well understood. This study analysed the effects of biochar pyrolysis temperature and application rate on the soil microbial community of loess. Two biochars derived from soybean stover were produced at 300 and $600^{\circ} \mathrm{C}(\mathrm{BC} 300$ and $\mathrm{BC} 600$, respectively) and were applied to loess at the rates of 1,3 , and $5 \%(\mathrm{w} / \mathrm{w})$. After fifteen weeks of incubation, soil microbial analysis was performed using $16 \mathrm{~S}$ rDNA amplicon sequencing technology. All of the BC300 and BC600 treated soils were shown to have an increase in the relative abundance of Gemmatimonadetes and a decrease in Actinobacteria and Chloroflexi. Proteobacteria also showed a significant increase in the majority of the biochar treated soils. Biochar led to a shift in the soil microbial community and caused a significant increase in the relative abundance of bacteria from the genus Lysobacter. Based on the results of this study, soybean stover-derived biochar should be considered as a potential soil amendment for improving the health of loess or other soils in semi-arid climates.
\end{abstract}

\section{INTRODUCTION}

The use of biochar, a carbon-rich material which results from the pyrolysis of biomass (Lehmann \& Joesph 2009), has gained much attention due to its potential benefits as a soil amendment.

Biochar has been shown to alter both the physical and chemical properties of soil (Verheijen et al. 2010). In doing so, biochar has the potential to increase land fertility by increasing soil $\mathrm{pH}$ (Prasad et al. 2018), water and nutrient retention (Verheijen et al. 2010), and soil organic matter (Han et al. 2016, Khadem \& Raiesi 2017). A growing number of studies also suggest that biochar can increase soil microbial biomass (Fox et al. 2014, Yao et al. 2017, Zhu et al. 2017a) and bacterial community network complexity (Zhou et al. 2018). However, there is still a lack of evidence for this and the interaction between biochar and soil microbial activity is not well understood (Zhu et al. 2017b). Some have also noted that by merely altering the physicochemical properties of soil, biochar can, therefore, indirectly cause shifts in the microbial community (Anderson et al. 2011). With this in mind, appropriate biochar pyrolysis temperatures and application rates need to be determined to provide sustainable and positive effects based on soil type, as well as other site-specific factors.

This study aimed to better understand the effects biochar has on soil microorganisms and how pyrolysis temperature and application rate influence these changes. The hypothesis was that the soils treated with soybean stover-derived biochar would cause an increase in soil microbial diversity due to its large surface area and potentially suitable habitat.

\section{MATERIALS AND METHODS}

\section{Soil Sampling and Analysis}

The loess used in this study was collected from the top $20 \mathrm{~cm}$ of a soybean field in the town of Santan (Jingyuan County) in China's Gansu Province. After the soil was collected, it was air-dried and passed through a $0.43 \mathrm{~mm}$ sieve.

$\mathrm{pH}$ value was measured, first, by weighing $20 \mathrm{~g}$ of sample and adding $50 \mathrm{~mL}$ of deionized water. Then, the sample was placed in a mechanical shaker for $30 \mathrm{~min}$ at $250 \mathrm{rpm}$. The sample was filtered and the $\mathrm{pH}$ value was measured using a PHS-3C pH meter from INESA Scientific Instrument Co., Ltd. EC was measured following the same process as $\mathrm{pH}$ except for $10 \mathrm{~g}$ of sample was used instead of $20 \mathrm{~g}$. EC was then measured using a DDS-11A conductivity meter from Hangzhou Aolilon Instrument Co., Ltd. Finally, SOM was tested using potassium dichromate oxidation according to the methods described by Chen \& Lu (2012).

The initial $\mathrm{pH}$, electrical conductivity (EC), and soil

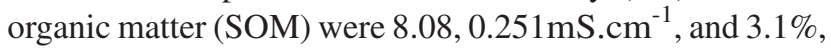
respectively. 


\section{Biochar Production and Characterization}

The soybean (Glycine max) stover that was used for biochar production was collected from a field in the town of Santan (Jingyuan County) in China's Gansu Province. After being collected, the stover was washed to remove impurities, airdried, and ground to pass through a $0.43 \mathrm{~mm}$ sieve. Biochar was then produced by placing the soybean stover biomass in a covered crucible and heating it in a muffle furnace (SX2, Shanghai Jiazhan Instrument Equipment Co., Ltd.) at $300^{\circ} \mathrm{C}$ and $600^{\circ} \mathrm{C}$ for 6 and $4 \mathrm{~h}$, respectively.

$\mathrm{C}, \mathrm{H}, \mathrm{N}$, and $\mathrm{S}$ content was determined using a combustion analyser (Vario Microcube, Elementar, Germany) and the BET surface area of both biochars was determined with a TriStar II surface area analyser (Micromeritics). SEM images were taken with a JSM-5600LV scanning electron microscope to compare the structures of BC300 and BC600. Ash content was tested by adding $1.0 \mathrm{~g}$ of biochar to a preweighed $30 \mathrm{~mL}$ crucible. The crucible was then heated in a muffle furnace until it reached $650^{\circ} \mathrm{C} \pm 20^{\circ} \mathrm{C}$. After cooling, the final weight of the ash and crucible was recorded and the ash content of BC300 and BC600 was calculated by the difference in the final weight and the pre-weighed crucible.

Pyrolysis temperature had a slight effect on the biochar's elemental composition, ash content, and $\mathrm{pH}$. The chemical characterization and properties of the $300^{\circ} \mathrm{C}$ and $600^{\circ} \mathrm{C}$ biochar (BC300 and BC600) are shown in Table 1. BC600 had a slightly higher carbon content, ash content, and $\mathrm{pH}$ when compared with BC300. Scanning electron microscopy (SEM) images were used to compare the structure of BC300 and BC600 (Fig. 1). BC600 had a relatively large BET surface area as $13.84 \mathrm{~m}^{2} \cdot \mathrm{g}^{-1}$, while BC300's surface area was only $2.00 \mathrm{~m}^{2} \cdot \mathrm{g}^{-1}$. However, it is unclear why BC600 did not have an even larger surface area. A soybean stover-derived bio- char with a much higher surface area $\left(420.33 \mathrm{~m}^{2} \cdot \mathrm{g}^{-1}\right.$ with a pyrolysis temperature of $700^{\circ} \mathrm{C}$ ) was reported by Ahmad et al. (2016a). Other studies (Windeatt et al. 2014, Khadem \& Raiesi 2017) also saw higher BET surface areas (from 88.4 to $222.5 \mathrm{~m}^{2} \cdot \mathrm{g}^{-1}$ ) with various types of biochars pyrolyzed at $600^{\circ} \mathrm{C}$. Nevertheless, the higher surface area of BC600 still, in theory, makes it a more suitable habitat for soil microbiota.

\section{Experimental Design}

BC300 and BC600 were added to $100 \mathrm{~g}$ of loess at the rates of 1,3 , and $5 \%(\mathrm{w} / \mathrm{w})$, with the control containing no biochar. These samples will be referred to as BC300-1, BC300-3, BC300-5, BC600-1, BC600-3, and BC600-5. Three replicates of each treatment were incubated for fifteen weeks at $25 \pm 1^{\circ} \mathrm{C}$. After fifteen weeks, the methods outlined as following were used to analyse changes and shifts in soil microbial community of each treatment group.

\section{DNA Extraction, Sequencing and PCR Amplification}

Microbial analysis was conducted using a 16S rDNA amplicon sequencing technology based on the IonS5TM XL sequencing platform. The genomic DNA of the sample was extracted using a CTAB extraction protocol, and then the purity and concentration of the DNA were detected by agarose gel electrophoresis. The appropriate amount of sample DNA was taken in a centrifuge tube and the sample was diluted to $1 \mathrm{ng} \cdot \mathrm{\mu L}^{-1}$ with sterile water. Phusion ${ }^{\circledR}$ High-Fidelity PCR Master Mix with GC Buffer (New England Biolabs) was used to perform all of the polymerase chain reactions (PCR).

PCR products were detected using a $2 \%$ agarose gel and electrophoresis. The samples were mixed according to the concentration of the PCR products. After thorough mixing, the PCR products were purified by electrophoresis using a $1 \times$ TAE concentration of $2 \%$ agarose gel. The products
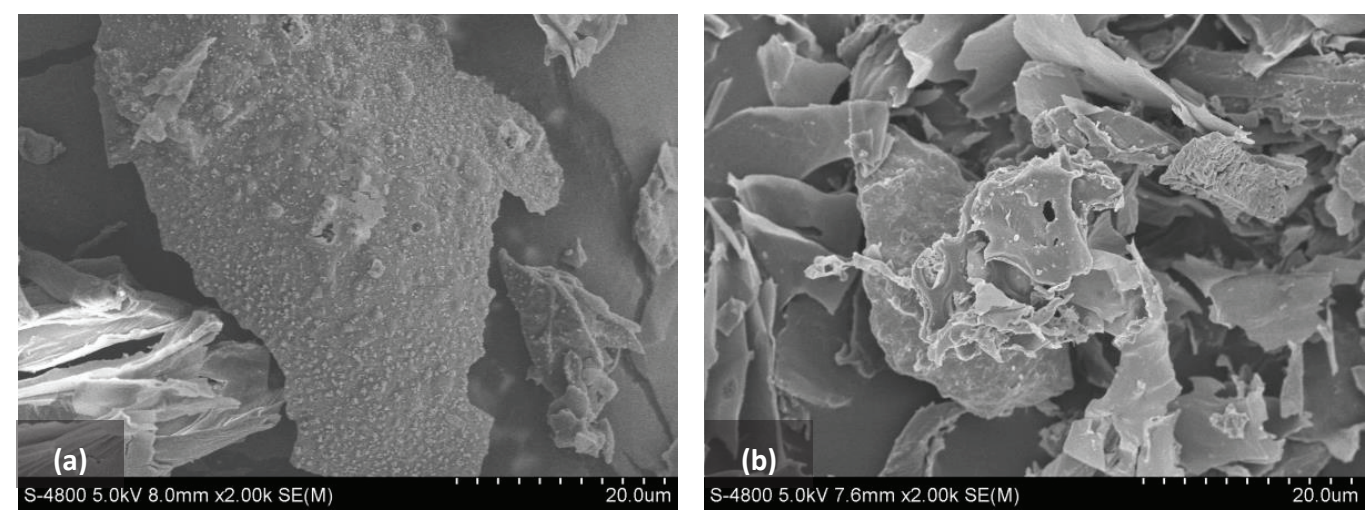

Fig. 1: SEM images at $20.0 \mu \mathrm{m}$ of BC300 and BC600 (a and b, respectively). 
were then purified using a GeneJET ${ }^{\mathrm{TM}}$ Gel Extraction Kit (Thermo Scientific).

Sequencing libraries were generated using Ion Plus Fragment Library Kit 48 rxns (Thermo Scientific) following the manufacturer's recommendations. The quality of the library was evaluated on the Qubit@ 2.0 Fluorometer (Thermo Scientific). Finally, the library was sequenced on an Ion $\mathrm{S} 5^{\mathrm{TM}} \mathrm{XL}$ platform and $400 \mathrm{bp} / 600 \mathrm{bp}$ single-end reads were generated.

\section{Data Processing}

Quality filtering on the raw reads was performed under specific filtering conditions to obtain the high-quality clean reads according to the command-line tool Cutadapt (Martin 2011). The reads were then compared with the Silva database project (Quast et al. 2013). UCHIME (Edgar et al. 2013) was used to detect and remove chimaera sequences (Haas et al. 2011). Clean reads were then finally obtained.

Sequence analysis was performed by UPARSE (version 7.0.1001) (Edgar et al. 2013) and sequences with $\geq 97 \%$ similarity were assigned to the same operational taxonomic units (OTUs).

\section{Statistical Analysis}

QIIME (version 1.7.0) was used for statistical analysis for this study. Bacterial community richness was identified using the Chao1 estimator and abundance-based coverage estimator
(ACE). Shannon and Simpson's indices were used to identify bacterial community diversity. Nonmetric multidimensional scaling (nMDS) (Kruskal 1964) was used to determine the variance in and overall effect on the bacterial community due to the addition of biochar. Linear discriminant analysis (LDA) effect size (LEfSe) (Segata et al. 2011) was also utilized to further analyse the metagenomic data.

\section{RESULTS AND DISCUSSION}

\section{The Effects of Biochar on Microbial Structure and Bacterial Diversity}

Variance in bacteria phyla distributions showed that the application of biochar did cause a shift in the microbial community of loess (Fig. 2). The majority of the control (81.9\%), BC300 treatments ( $83.4 \%$ to $86.9 \%)$, and BC600 treatments $(85.6 \%$ to $87.1 \%)$ were all mainly associated with five different bacteria phyla (Proteobacteria, Gemmatimonadetes, Actinobacteria, Bacteroidetes, and Chloroflexi). This trend in soil bacterial community is similar to studies conducted by Ahmad et al. (2016b) and Kolton et al. (2011). However, the results of this study were less pronounced. Every treatment, except for BC300-1, showed an increase in the relative abundance of Proteobacteria from the control (27.3\%) with BC300-5 and BC600-5 being the highest at $34.2 \%$ and $35.2 \%$, respectively. The relative abundance of Gemmatimonadetes increased significantly in all biochar

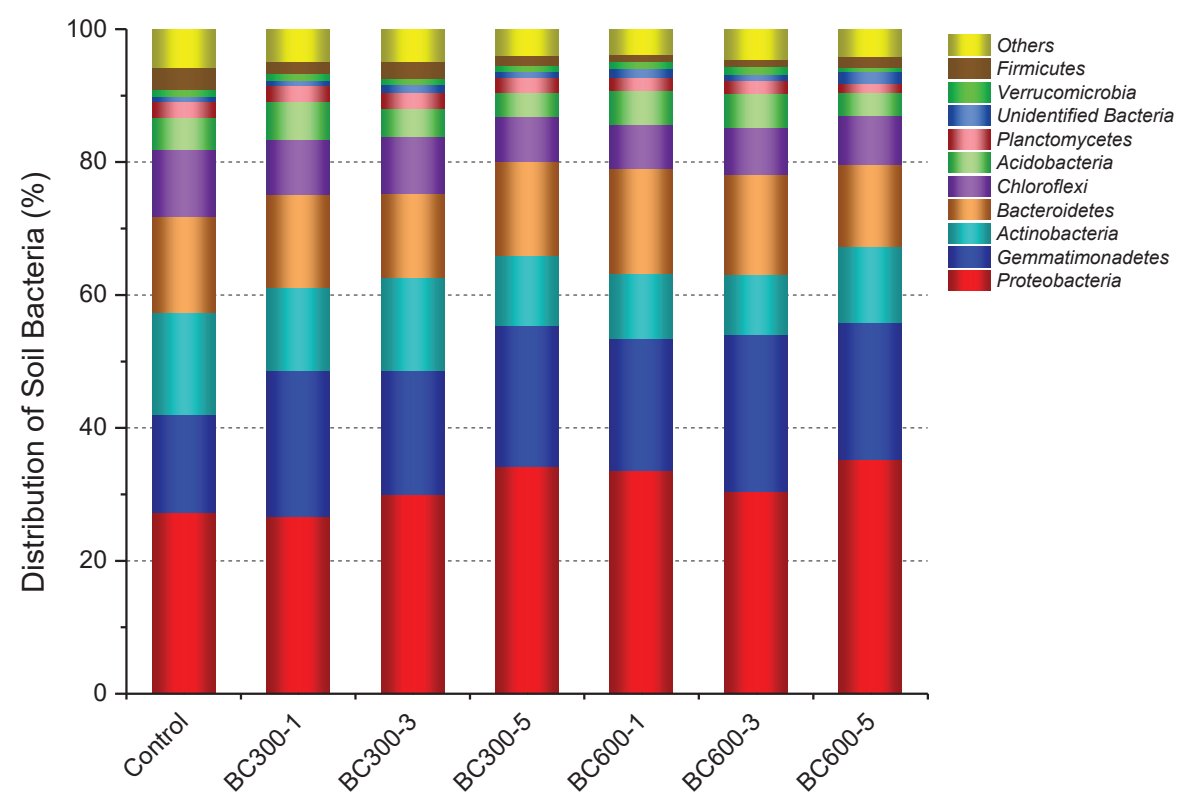

Fig. 2: Distribution of soil bacteria phyla from soils treated with BC300 and BC600. 
a)

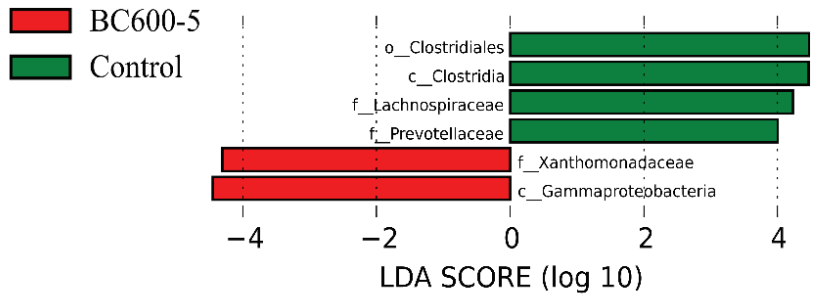

b)

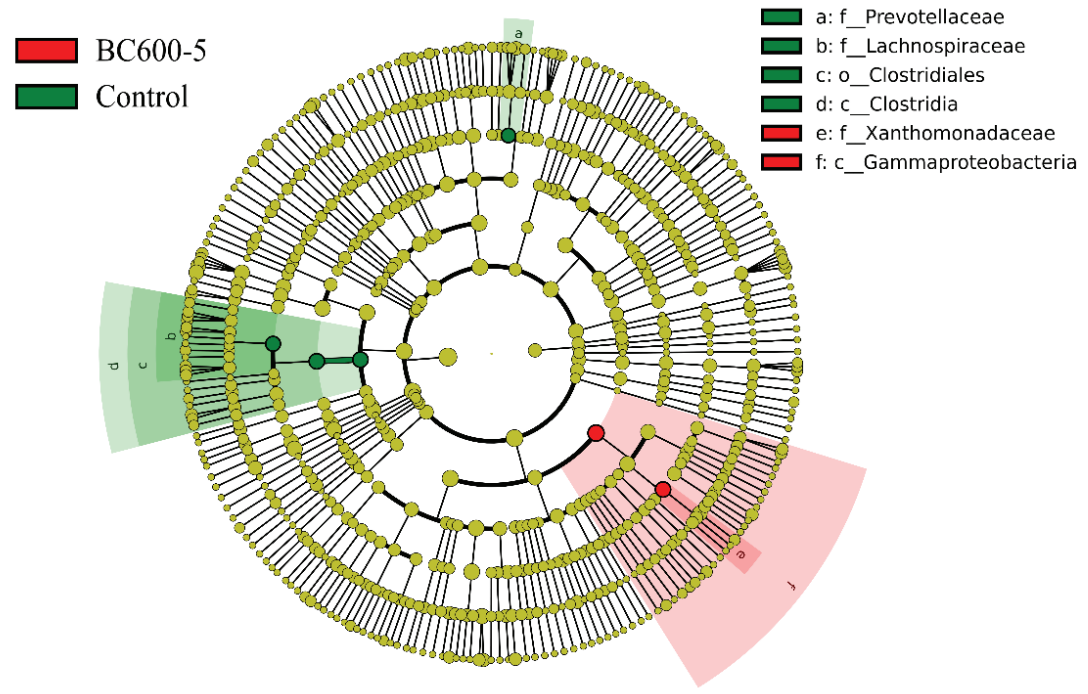

Fig. 3: LEfSe comparison between the control and BC600-5: (a) Effect size of class variations with LDA scores greater than 4, (b) Cladogram of phylogenic distributions based on class.

treatments where $\mathrm{BC} 300-1$ and $\mathrm{BC} 600-3$ were the most notably different than the control $(14.6 \%)$ at $22.0 \%$ and $23.6 \%$, respectively. Actinobacteria and Chloroflexi both saw small reductions in relative abundance with the addition of biochar whereas Bacteroidetes and Acidobacteria saw little to no change. Ahmad et al. (2016b) also reported a similar decrease in Chloroflexi and increase in Proteobacteria with the addition of soybean and peanut stover-derived biochars. The study conducted by Kolton et al. (2011), on the other hand, saw a significant decrease in Proteobacteria and a significant increase in Bacteroidetes with the addition of citrus wood biochar. These variances in results are most likely due to different types of biomass, pyrolysis temperatures, and soil types.

The total observed species, diversity indices, richness estimators, and Good's coverage values are shown in Table 2. BC300-3 had the highest number of observed species at $2,767 \pm 196$ with the control and BC600-3 slightly lower at 2,728 \pm 466 and 2,723 \pm 132 , respectively. The Good's coverage values (0.991-0.996) were all very high indicating the number of sequencing reads was sufficient in covering the full diversity of the samples. The Shannon and Simpson diversity indices showed that $\mathrm{BC} 300-3$ had the highest bacterial diversity and that the rest of the biochar treatments were either slightly higher or similar to the control. BC600-5 was shown to have the highest bacterial richness based on Chao1 and ACE richness indices. The bacterial richness of the other treatments were either slightly lower or similar to the control.

\section{Shifts in Microbial Community Based on LEfSe Analysis}

LEfSe was used to further analyse the impact of biochar on soil microbial community. The first comparison made was between BC600-5 and the control. The results showed that BC600-5 and the control's variations occurred between not only different classes of bacteria, but different phyla of bacteria (Proteobacteria, Bacteroidetes and Firmicutes, 

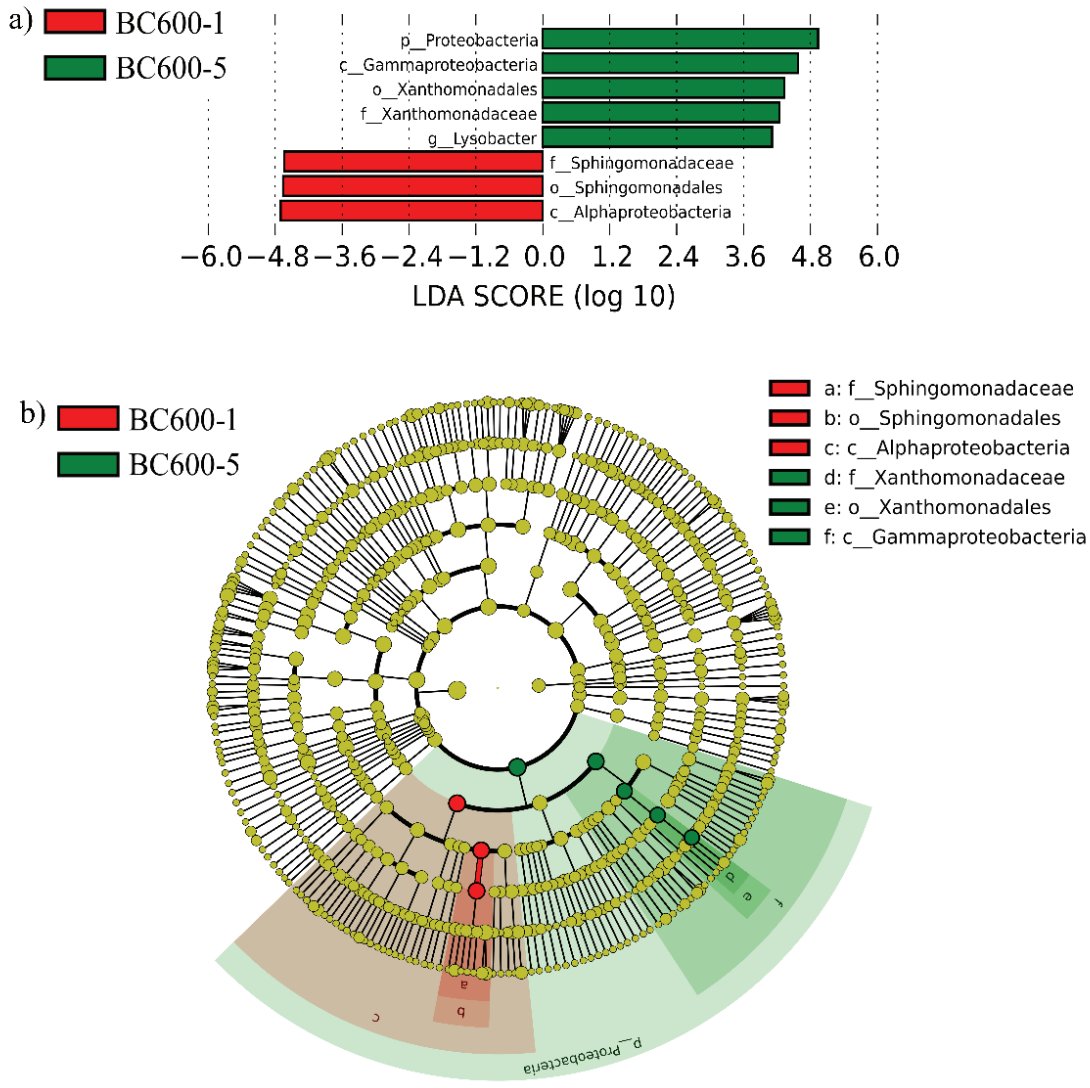

Fig. 4: LEfSe comparison between the BC600-1 and BC600-5: (a) Effect size of class variations with LDA scores greater than 4, (b) Cladogram of phylogenic distributions based on class.

respectively). This again shows that application of biochar, specifically BC600 in this case, led to a shift in the structure of the microbial community. The variations between these two samples can be seen in Fig. 3. The rings in the cladograms (Figs. $3 \mathrm{~b}$ and $4 \mathrm{~b}$ ) from inside out represent phylogenic level from phylum to species.

The second comparison was made between B600-1 and BC600-5. This was done to compare the variance between two biochar groups when different application rates were used. The variations between these two samples, which are shown in Fig. 4, are from two different classes stemming from the phylum Proteobacteria. BC600-1 was associated with bacteria from the class Alphaproteobacteria and order Sphingomonadales, whereas BC600-5 was associated with bacteria from the class Gammaproteobacteria and order Xanthomonadales. BC600-5 had the highest relative abundance of bacteria from the genus Lysobacter (the relative abundance of each sample can be seen in Fig. 5), which proves significant for a variety of reasons. First, bacteria from the genus Lysobacter have been shown to suppress damping-off disease (Islam et al. 2005); a disease which affects a variety of crops including soybeans (Zitnick-Anderson et al. 2014). Second, research has also proven bacteria from this genus can be used as a means of biological control against various soybean fungal diseases (Nian 2015). Third, Lysobacter has been found in soybean cyst nematodes and could be used as a potential biocontrol agent against such cysts (Nour et al. 2003). BC300-5 (cladogram not shown) also showed similar

Table 1: Physical and chemical characterization of BC300 and BC600.

\begin{tabular}{|c|c|c|c|c|c|c|c|c|}
\hline & \multicolumn{5}{|c|}{ Elemental Composition (\%) } & \multirow[b]{2}{*}{$\operatorname{Ash}(\%)$} & \multirow[b]{2}{*}{$\mathrm{pH}$} & \multirow[b]{2}{*}{ BET Surface Area $\left(\mathrm{m}^{2} \cdot \mathrm{g}^{-1}\right)$} \\
\hline & $\mathrm{C}$ & $\mathrm{H}$ & $S$ & $\mathrm{~N}$ & $\mathrm{O}$ & & & \\
\hline BC 300 & 66.43 & 3.51 & 0.53 & 1.58 & 14.46 & 13.5 & 7.87 & 2.00 \\
\hline ВС600 & 74.23 & 1.59 & 0.58 & 1.46 & 6.64 & 15.5 & 8.42 & 13.84 \\
\hline
\end{tabular}




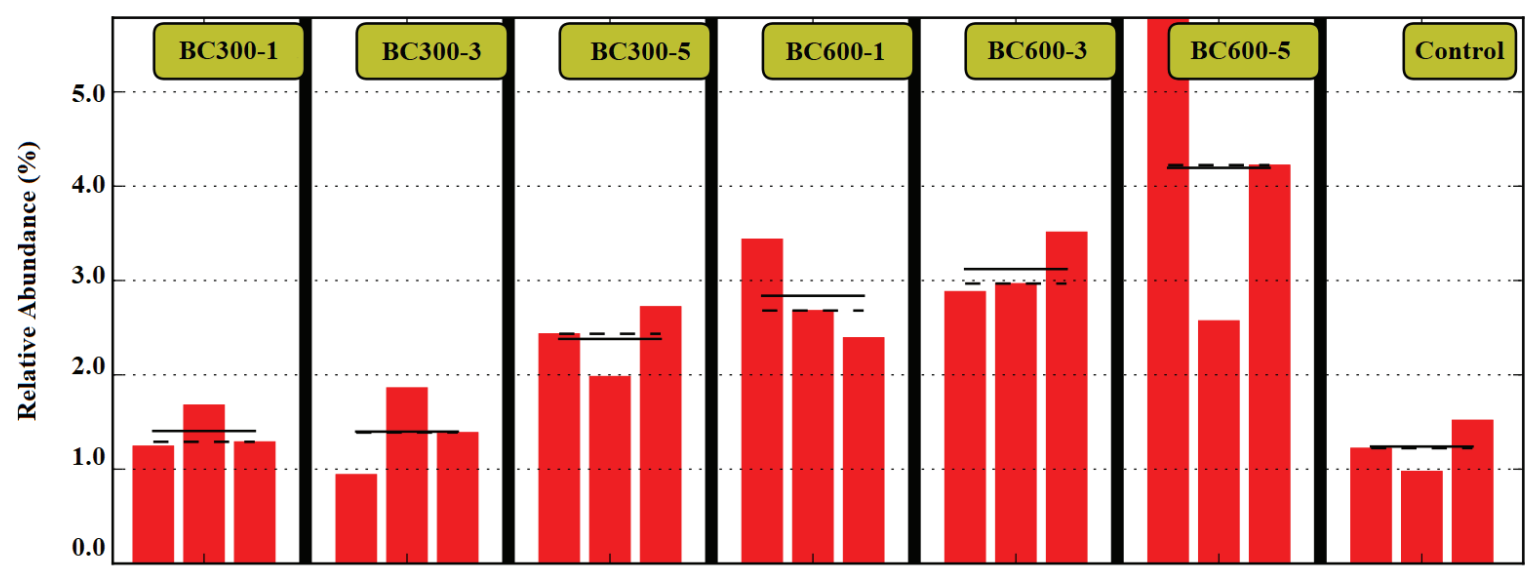

Fig. 5: Relative abundance of bacteria from the genus Lysobacter (LEfSe biomarkers).

variations from the control with differences stemming from the class Proteobacteria.

The fact that BC600-5 and the control had more variance than BC600-1 and BC600-5 shows that the microbial communities of biochar amended soils were more similar in structure. This also supports the idea that biochar can significantly influence the structure of microbial communities in loess.

\section{Nonmetric Multidimensional Scaling (nMDS) Analysis}

nMDS analysis, based on OTU level, showed that biochar addition did cause a statistically significant change in the bacterial community, especially when considering pyrolysis temperature. BC300-1 and BC300-3 were more like the control whereas the other treatments showed more variance. When
BC300 and BC600 were added at 5\%, there also appeared to be more variance than with $1 \%$ and $3 \%$ amendments. The nMDS plot grouped by the various biochar treatments can be seen in Fig. 6.

\section{CONCLUSIONS}

The results of this study showed that soybean stover-derived biochar caused shifts in the soil microbial community of loess and in some samples led to higher bacterial diversity and richness. Based on LEfSe analysis, BC600 was shown to provide the most suitable habitat for bacteria from the genus Lysobacter. The higher BET surface area and $\mathrm{pH}$ of BC600 most likely led to changes seen in microbial structure and the increase in the relative abundance of Lysobacter.

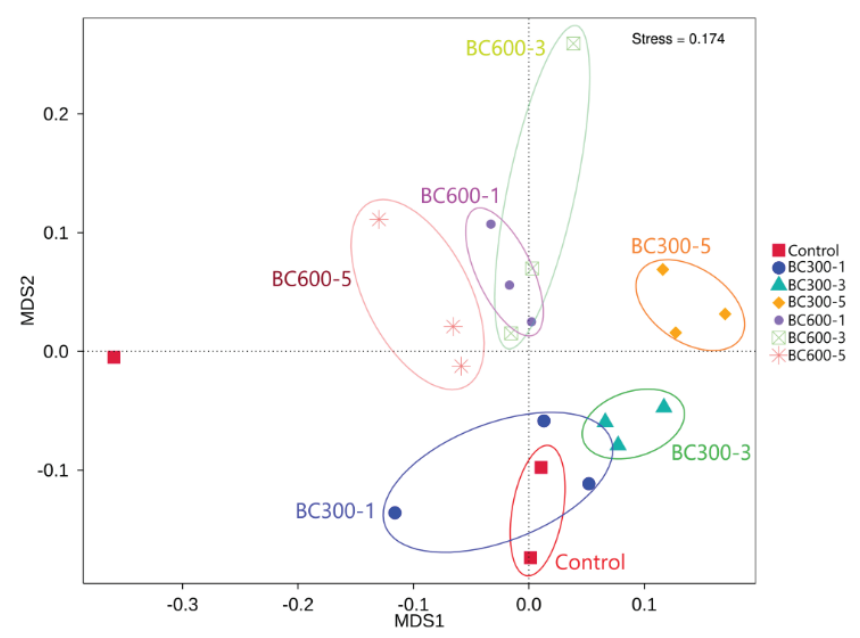

Fig. 6: nMDS plot based on OTU level from soils treated with BC300 and BC600. 
Table 2: Summary of sequencing data from soils treated with BC300 and BC600.

\begin{tabular}{|c|c|c|c|c|c|c|}
\hline & \multirow{2}{*}{ Observed Species } & \multicolumn{2}{|c|}{ Diversity Index } & \multicolumn{2}{|c|}{ Richness Estimator } & \multirow{2}{*}{ Good's Coverage } \\
\hline & & Shannon & Simpson & Chao1 & $\mathrm{ACE}$ & \\
\hline Control & $2728 \pm 466$ & $8.921 \pm 1.294$ & $0.983 \pm 0.024$ & $2914.12 \pm 451.85$ & $2919.43 \pm 446.70$ & $0.995 \pm 0$ \\
\hline BC300-1 & $2670 \pm 135$ & $9.206 \pm 0.533$ & $0.992 \pm 0.008$ & $2857.47 \pm 130.16$ & $2858.73 \pm 123.73$ & $0.995 \pm 0.001$ \\
\hline ВС $300-3$ & $2767 \pm 196$ & $9.529 \pm 0.199$ & $0.996 \pm 0.001$ & $2954.89 \pm 182.25$ & $2955.65 \pm 188.26$ & $0.995 \pm 0$ \\
\hline ВС $300-5$ & $2562 \pm 120$ & $9.29 \pm 0.024$ & $0.996 \pm 0$ & $2760.80 \pm 140.28$ & $2760.87 \pm 151.27$ & $0.995 \pm 0.001$ \\
\hline BC600-1 & $2667 \pm 131$ & $9.103 \pm 0.246$ & $0.995 \pm 0.001$ & $2881.97 \pm 114.87$ & $2891.95 \pm 121.17$ & $0.995 \pm 0.001$ \\
\hline ВC600-3 & $2723 \pm 132$ & $9.254 \pm 0.042$ & $0.995 \pm 0.001$ & $2906.38 \pm 153.33$ & $2913.67 \pm 144.29$ & $0.995 \pm 0.001$ \\
\hline ВC600-5 & $2670 \pm 267$ & $9.125 \pm 0.355$ & $0.995 \pm 0.002$ & $3370.22 \pm 1077.31$ & $2962.14 \pm 401.58$ & $0.994 \pm 0.003$ \\
\hline
\end{tabular}

Soybean stover-derived biochar should be considered as a soil amendment due to its positive effect on the microbial community in loess.

\section{ACKNOWLEDGEMENT}

This work was financially supported by the National Natural Science Foundation of China (51766008, 21467013, 21167007).

\section{REFERENCES}

Ahmad, M., Ok, Y. S., Rajapaksha, A. U., Lim, J. E., Kim B-Y., Ahn, J-H., Lee, Y. H., Al-Wabel, M., Lee, S-E. and Lee, S. S. 2016a. Lead and copper immobilization in a shooting range soil using soybean stover- and pine needle-derived biochars: Chemical, microbial and spectroscopic assessments. J. Hazard. Mater., 301(1): 179-186.

Ahmad, M., Ok, Y. S., Kim, B., Ahn, J-H., Lee, Y. H., Zhang, M., Moon, D. H., Al-Wabel, M. I. and Lee, S. S. 2016b. Impact of soybean stover- and pine needle-derived biochars on $\mathrm{Pb}$ and As mobility, microbial community, and carbon stability in a contaminated agricultural soil. J. Environ. Manage., 166(1): 131-139.

Anderson, C. R., Condron, L. M., Clough, T. J., Fiers, M., Stewart, A., Hill, R. A. and Sherlock, R. R. 2011. Biochar induced soil microbial community change : Implications for biogeochemical cycling of carbon, nitrogen and phosphorus. Pedobiologia-Int. J. Soil Biol., 54(5-6): 309-320.

Chen, D. and Lu, J. 2012. Low-temperature external-heat potassium dichromate oxidation-photo-colorimetric method for determination of organic carbon in dewatering sludge. Yunnan Chem Technol., (1): 39-42, 50.

Edgar, R. C. 2013. UPARSE: Highly accurate OTU sequences from microbial amplicon reads. Nat. Methods, 10(10): 996-998.

Edgar, R. C., Haas, B. J., Clemente, J. C., Quince, C. and Knight, R. 2011. UCHIME improves sensitivity and speed of chimera detection. Bioinformatics, 27(16): 2194-2200.

Fox, A., Kwapinski, W., Griffiths, B. S. and Schmalenberger, A. 2014. The role of sulfur- and phosphorus-mobilizing bacteria in biochar-induced growth promotion of Lolium perenne. FEMS Microbiol. Ecol., 90(1): 78-91.

Haas, B. J., Gevers, D., Earl, A. M., Feldgarden, M., Ward, D. V., Giannoukos, G., Ciulla, D., Tabbaa, D., Highlander, S. K., Sodergren, E., Methé, B. and DeSantis, T. Z. 2011. Chimeric 16S rRNA sequence formation and detection in Sanger and 454-pyrosequenced PCR amplicons. Genome Res., 21(3): 494-504.

Han, F., Ren, L. and Zhang, X. C. 2016. Effect of biochar on the soil nutrients about different grasslands in the Loess Plateau. Catena, 137: 554-562. Islam, M. T., Hashidoko, Y., Deora, A., Ito, T. and Tahara, S. 2005. Suppression of damping-off disease in host plants by the rhizoplane bacterium Lysobacter sp. strain SB-K88 is linked to plant colonization and antibiosis against soilborne peronosporomycetes. Appl. Environ. Microbiol., 71(7): 3786-3796.

Khadem, A. and Raiesi, F. 2017. Responses of microbial performance and community to corn biochar in calcareous sandy and clayey soils. Appl. Soil Ecol., 114(1): 16-27.

Kolton, M., Harel, Y. M., Pasternak, Z., Graber, E. R., Elad, Y. and Cytryn, E. 2011. Impact of biochar application to soil on the root-associated bacterial community structure of fully developed greenhouse pepper plants. Appl. Environ. Microbiol., 77(14): 4924-4930.

Kruskal, J. B. 1964. Nonmetric multidimensional scaling: A numerical method. Psychometrika, 29(2): 115-129.

Lehmann, J. and Joseph, S. 2009. Biochar for Environmental Management: An Introduction. Earthscan.

Martin, M. 2011. Cutadapt removes adapter sequences from high-throughput sequencing reads. EMBnet. J., 17(1): 10-12.

Nian J. 2015. Evaluation of Lysobacter Enzymogenes C3 for Control of Soybean Fungal Diseases. University of Illinois at Urbana-Champaign.

Nour, M. S., Lawrence, J. R., Zhu, H., Swerhone, G. D. W., Welsh, M., Welacky, T. W. and Topp, E. 2003. Bacteria associated with cysts of the soybean cyst nematode (Heterodera glycines). Appl. Environ. Microbiol., 69(1): 607-615.

Prasad, M., Tzortzakis, N. and McDaniel, N. 2018. Chemical characterization of biochar and assessment of the nutrient dynamics by means of preliminary plant growth tests. J. Environ. Manage., 216: 89-95.

Quast, C., Pruesse, E., Yilmaz P, Gerken, J., Schweer, T., Yarza, P., Peplies, J. and Glöckner, F. O. 2013. The SILVA ribosomal RNA gene database project: Improved data processing and web-based tools. Nucleic Acids Res., 41(D1): D590-D596.

Segata N, Izard J, Waldron L, Gevers, D., Miropolsky, L., Garrett, W. S. and Huttenhower, C. 2011. Metagenomic biomarker discovery and explanation. Genome Biol., 12(6): R60.

Verheijen, F., Jeffery, S., Bastos, A. C., Velde, M. van der and Diafas, I. 2010. Biochar Application to Soils - A Critical Scientific Review of Effects on Soil Properties, Processes and Functions. European Commission.

Windeatt, J. H., Ross, A. B., Williams, P. T., Forster, P. M., Nahil, M. A. and Singh, S. 2014. Characteristics of biochars from crop residues: Potential for carbon sequestration and soil amendment. J. Environ. Manage., 146(1): 189-197.

Yao, Q., Liu, J., Yu, Z, Li, Y., Jin, J., Liu, X. and Wang, G. 2017. Changes of bacterial community compositions after three years of biochar application in a black soil of northeast China. Appl. Soil Ecol., 113(1): 11-21.

Zhou, Z., Gao. T., Zhu, Q., Yan, T., Li, D., Xue, J. and Wu, Y. 2019. Increases 
in bacterial community network complexity induced by biochar-based fertilizer amendments to karst calcareous soil. Geoderma, 337: 691-700.

Zhu, L., Xiao, Q., Cheng, H., Shi, B., Shen, Y. and Li, S. 2017a. Seasonal dynamics of soil microbial activity after biochar addition in a dryland maize field in North-Western China. Ecol. Eng., 104(1): 141-149.
Zhu, L., Xiao, Q., Shen, Y. and Li, S. 2017b. Microbial functional diversity responses to 2 years since biochar application in silt-loam soils on the Loess Plateau. Ecotoxicol. Environ. Saf., 144: 578-584.

Zitnick-Anderson, K., Markell, S. and Nelson, Jr. B. 2014. Pythium Damping-off of Soybean. North Dakota State University. 